\title{
Screening for adulticidal activity against Anopheles arabiensis in ten plants used as mosquito repellent in South Africa
}

\author{
Edison J Mavundza ${ }^{1,2^{*}}$, Rajendra Maharaj ${ }^{1}$, Jude C Chukwujekwu ${ }^{2}$, Jeffrey F Finnie ${ }^{2}$ and Johannes Van Staden ${ }^{2^{*}}$
}

\begin{abstract}
Background: Due to the development of resistance to synthetic insecticides, adverse effects to human health, non-target organisms and the environment, there is an urgent need to develop new insecticides, which are effective, safe, biodegrable and target-specific. This study was undertaken to evaluate the adulticidal activity of 10 plants used traditionally as mosquito repellents in South Africa.
\end{abstract}

Methods: The dried plant materials were extracted with dichloromethane (DCM) and ethanol (EtOH). The extracts were evaluated for adulticidal activity against Anopheles arabiensis mosquitoes, a potent malaria vector in South Africa. Adult mortality was observed after 24 hours of exposure.

Results: All the extracts showed adulticidal activity. The highest activity was observed in both DCM and EtOH extracts of Aloe ferox leaves with 98 and 86\% mosquito mortality, respectively. The DCM extract of $A$. ferox leaves was then subjected to a dose-dependent bioassay to determine the $\mathrm{EC}_{50}$ value. The extract exhibited an $\mathrm{EC}_{50}$ value of $4.92 \mathrm{mg} / \mathrm{ml}$.

Conclusion: The results of the present study showed that the DCM extract of $A$. ferox leaves may have the potential to be used as an insecticide against An. arabiensis. Further studies to isolate and identify active compounds are in progress.

Keywords: Malaria, Mosquitoes, Anopheles arabiensis, Adulticidal, Aloe ferox

\section{Background}

Mosquito-borne diseases, such as malaria, Japanese encephalitis, filariasis, dengue and yellow fever remain a major source of illness and death worldwide, particularly in tropical and subtropical countries [1]. It is estimated that more than 700 million people are infected with mosquito-transmitted diseases annually [2]. Among these diseases, malaria, which is caused by parasites of the genus Plasmodium and transmitted by the bite of infected female mosquitoes of the genus Anopheles, continues to be a major public health problem in tropical and subtropical countries, despite decades of control efforts. In 2010, the World Health Organization (WHO) estimated that there

\footnotetext{
* Correspondence: edison.mavundza@mrc.ac.za; rcpgd@ukzn.ac.za
${ }^{1}$ Malaria Research Unit, Medical Research Council, 491 Peter Mokaba Ridge,

* Correspondence: edison.mavundza@mrc.ac.za; rcpgd@ukzn.ac.za
${ }^{1}$ Malaria Research Unit, Medical Research Council, 491 Peter Mokaba Ridge, Overport, Durban 4001, South Africa

${ }^{2}$ Research Centre for Plant Growth and Development, School of Life
Sciences, University of KwaZulu-Natal Pietermaritzburg, Private Bag X01,

${ }^{2}$ Research Centre for Plant Growth and Development, School of Life
Sciences, University of KwaZulu-Natal Pietermaritzburg, Private Bag X01, Scottsville 3209, South Africa
}

were 216 million cases of malaria and 655,000 deaths worldwide. About $91 \%$ of these deaths occurred in subSaharan Africa, and were mostly in children under five years of age [3].

Despite significant efforts to control malaria in South Africa since 1930 [4], the disease remains a serious health problem [5]. An estimated 4.3 million people are at risk of contracting malaria [4]. In 2000, the highest number $(61,934)$ of malaria cases were reported, the worst levels of malaria recorded since the epidemics of the 1930s [6]. In South Africa, malaria is currently confined to the lowaltitude regions of Limpopo, Mpumalanga and KwaZuluNatal provinces, in the north-eastern part of the country, along the border with Mozambique and Swaziland. Malaria transmission in South Africa is distinctly seasonal [7,8], with Anopheles arabiensis being the major vector [5].

Since there is currently no effective vaccine available for the prevention of malaria, vector control is the main 
strategy used to control this disease. IRS (indoor residual spraying), which is the application of insecticides on the walls and ceilings of residential structures in order to kill and/or repel the adult vector mosquitoes that land and rest on these surfaces, is one of the primary vector control methods for reducing and interrupting malaria transmission [9]. Presently, IRS primarily depends on applications of synthetic insecticides. There are currently 12 insecticides belonging to four chemical groups recommended by WHO for IRS, namely, organochlorides, organophosphates, carbamates and pyrethroids. Among these insecticides, DDT (1,1,1-trichloro-2,2-bis (4-chlorophenyl) ethane), an organochloride, is the one with the longest residual efficacy (6-12 months depending on dosage and substrate) $[9,10]$. DDT was introduced into malaria control programmes in the 1940s [11], and it has been effective in reducing malaria morbidity and mortality in South Africa [12]. It also contributed to the eradication of malaria in the United States, Japan, Korea, Taiwan, Spain, Italy, the Balkans, Greece and Northern Africa during the Global Malaria Eradication Programme (GMEP) of 1955$1969[13,14]$. Despite its effectiveness in reducing malaria, the use of DDT has resulted in many problems such as, adverse effects on the environment, human health, nontarget organisms, and the development of insecticide resistance in mosquito populations [15]. There is, therefore, an urgent need to develop new insecticides, which are effective, safe, biodegradable and target-specific.

Plants may be an alternative source of mosquitocontrol agents because they constitute a rich source of bioactive chemicals [16,17]. Natural products are generally preferred because of their less harmful nature to non-target organisms and due to their innate biodegradability $[16,18]$. Humans have used plants to control insects since time immemorial [19], even before the discovery of synthetic organic insecticides [20]. Much effort has, therefore, been focused on plant extracts or phytochemicals as potential sources of mosquito insecticidal agents or as lead compounds. Today, over 2000 plant species are known to possess insecticidal activities [21-23]. In view of the recently increased interest in developing plant-derived insecticides, the present study was undertaken to assess the adulticidal potential against Anopheles arabiensis of 10 extracts from the selected plants that are reportedly used traditionally as mosquito repellents in South Africa [24].

\section{Methods}

\section{Plant collection}

Plant materials (Table 1) were collected from Ndumo Village, in uMkhanyakude district, KwaZulu-Natal Province, South Africa. Voucher specimens were prepared and deposited at the Bews Herbarium, University of KwaZulu-Natal, Pietermaritzburg Campus.

\section{Preparation of plant extracts}

Plant materials were dried in an oven at $30-60^{\circ} \mathrm{C}$. The drying time and temperature varied depending on the nature of the plant material. The dried plant materials were ground into powders by an electrical blender and stored in airtight containers under dark conditions at room temperature. The ground plant materials were extracted separately with $20 \mathrm{ml} / \mathrm{g}$ of ethanol $(\mathrm{EtOH})$ and dichloromethane (DCM) by sonication for 1 hour. The extracts were filtered through Whatman No. 1 filter paper and concentrated under vacuum using a rotary evaporator (Büchi, Germany) at $30^{\circ} \mathrm{C}$. The concentrated extracts were dried at room temperature under a stream of cold air. The dried extracts were stored at $4^{\circ} \mathrm{C}$ in the dark until required for assays.

\section{Rearing mosquitoes}

The adulticidal activity of plant extracts was evaluated using laboratory-reared An. arabiensis mosquitoes, a potent malaria vector in South Africa. The mosquitoes were obtained from a permanent colony maintained at $27 \pm 2^{\circ} \mathrm{C}$ and $85 \%$ relative humidity in the insectary of the Malaria Research Unit, Medical Research Council,

Table 1 Plants screened for adulticidal activity against Anopheles arabiensis

\begin{tabular}{|c|c|c|c|c|c|}
\hline Family & Botanical name & Common name & Local name & Voucher number & Part used \\
\hline Xanthorrhoeaceae & Aloe ferox Mill. & Cape aloe & iNhlaba & EM08 & Leaves \\
\hline Anacardiaceae & Sclerocarya birrea (A.Rich.) Hochst. & Marula & Umango & EM10 & Leaves \\
\hline Balanitaceae & Balanites maughamii Sprague. & Torchwood & uGobendlovu & EM09 & Bark \\
\hline Euphorbiaceae & Croton menyaarthii Pax & Rough-leaved Croton & Hubeshani & EM05 & Leaves \\
\hline Meliaceae & Melia azedarach L. & Chinaberry & Umsilinga & EM01 & Leaves \\
\hline Meliaceae & Trichilia emitica Vahl & Natal Mahogany & Umkhuhlu & EM06 & Leaves \\
\hline Olacaceae & Olax dissitiflora Oliver & Bastard Sourplum & Mampuzane & EM04 & Bark \\
\hline Rutaceae & Clausena anisata (Willd.) Hook.F. & Perdepis & Umsanga & EM02 & Leaves \\
\hline Sapindaceae & Atalaya alata (Sim) H.H.L. Forbes & Lebombo krantz Ash & Umnondo & EM07 & Leaves \\
\hline Verbenaceae & Lippia javanica (Brum.f) Spreng. & Fever tea & Umsuzwane & EM03 & Leaves \\
\hline
\end{tabular}


Durban, South Africa. Larvae were fed on dog biscuits and yeast powder at a 3:1 ratio. Adults were provided with a $10 \%$ sucrose solution. Female mosquitoes were periodically blood-fed on restrained albino guinea pigs for egg production. The guinea pigs were reared according to the National Research Council's guidelines for the care and use of laboratory animals [25].

\section{Adulticidal assay}

The adulticidal activity of the plant extracts was evaluated following the WHO standard method with slight modifications [26]. Briefly, plant extracts were dissolved in acetone to prepare a testing concentration of $10 \mathrm{mg} /$ $\mathrm{ml}$. Two and half millilitres $(2.5 \mathrm{ml})$ of testing concentration was impregnated into Whatman No 1. filter papers $(12 \times 15 \mathrm{~cm})$. Acetone was used as a negative control while deltametrin (K-Othrine) was used as a positive control. The impregnated papers were air dried for $5 \mathrm{mi}$ nutes and then inserted into an exposure tube in the WHO testing kit. Twenty, 2-5 day old, blood-starved female mosquitoes were introduced into the holding tube and held for 1 hour to acclimatize. The mosquitoes were then transferred by gentle blowing in the exposure tube. After 1 hour in the exposure tube, mosquitoes were then transferred back to the holding tube to recover. A pad of cotton soaked with $10 \%$ glucose solution was placed on the mesh screen to feed recovering mosquitoes. At the end of the 24 hour recovery period, the number of dead mosquitoes was recorded and the percentage mortality was calculated. Each extract was tested in duplicate and the assay was repeated three times.

\section{Results and discussion}

The results of the adulticidal activities against $A n$. arabiensis of dichloromethane and ethanol extracts of 10 plants that are used as mosquito repellents in South
Africa are presented in Figure 1. All the extracts showed adulticidal activity after 24 hours of exposure with mosquito mortality ranging from 4 to $98 \%$. Three levels were used to define the activity of extracts: $1-49 \%$ low, $50-69 \%$ moderate and 70-100\% high. Of the highly active extracts, the DCM extract of Aloe ferox leaves exhibited the highest activity with 98\% adult mortality, followed by $\mathrm{EtOH}$ extracts of $A$. ferox leaves (86\%) and Atalaya alata (70\%). No activity was observed in the negative control, while the positive control exhibited $100 \%$ adult mortality. The high adulticidal activity shown by DCM extract of $A$. ferox leaves against $A n$. arabiensis is not surprising since it has been reported as a multipurpose traditional medicine. The plant is traditionally used as a laxative, emetics, to treat arthritis, sinusitis, conjunctivitis, opthalmia, herpes, shingles, sore throat, red water hypertensions, infertility in women and impotance in men. Furthermore, it has also been reported to possess antioxidant, antimicrobial, anti-inflammatory, anticancer, antimalarial, and anthelmintic activities [27].

These findings are comparable to those of Nathan et al. [28], who reported the adulticidal activity of methanol extract of Dysoxylum malabaricum leaves against Anopheles stephensi. The adulticidal activity of ethanol extract of Apium graveolens seeds against Aedes aegypti has been reported [29]. Kovendan et al. [30] found the adulticidal activity of methanol extract of Acalypha alinifolia leaves against three mosquito species, Ae. aegypti, An. stephensi and Culex quinquefasciatus. Other plant species that are reported to possess adulticidal activity includes: Curcuma aromatic against Ae. aegypti [31]; Aristolocia indica, Dolichos biflorus and Zingiber zerumbet against Culex gelidus and Cx. quinquefasciatus [32]; and Melia azedarach against An. stephensi [33].

Due to its high activity, the DCM extract of $A$. ferox leaves was then subjected to a dose-dependent bioassay

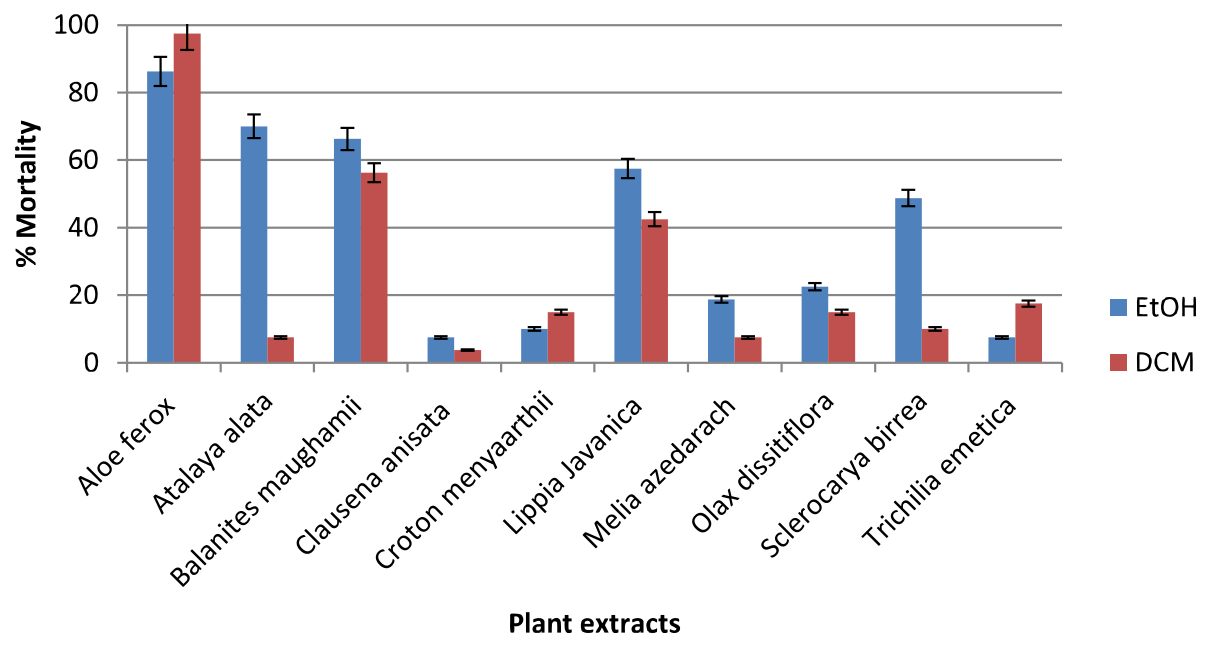

Figure 1 Adulticidal activity of DCM and EtOH extracts against An. arabiensis at $10 \mathrm{mg} / \mathrm{ml}$. 


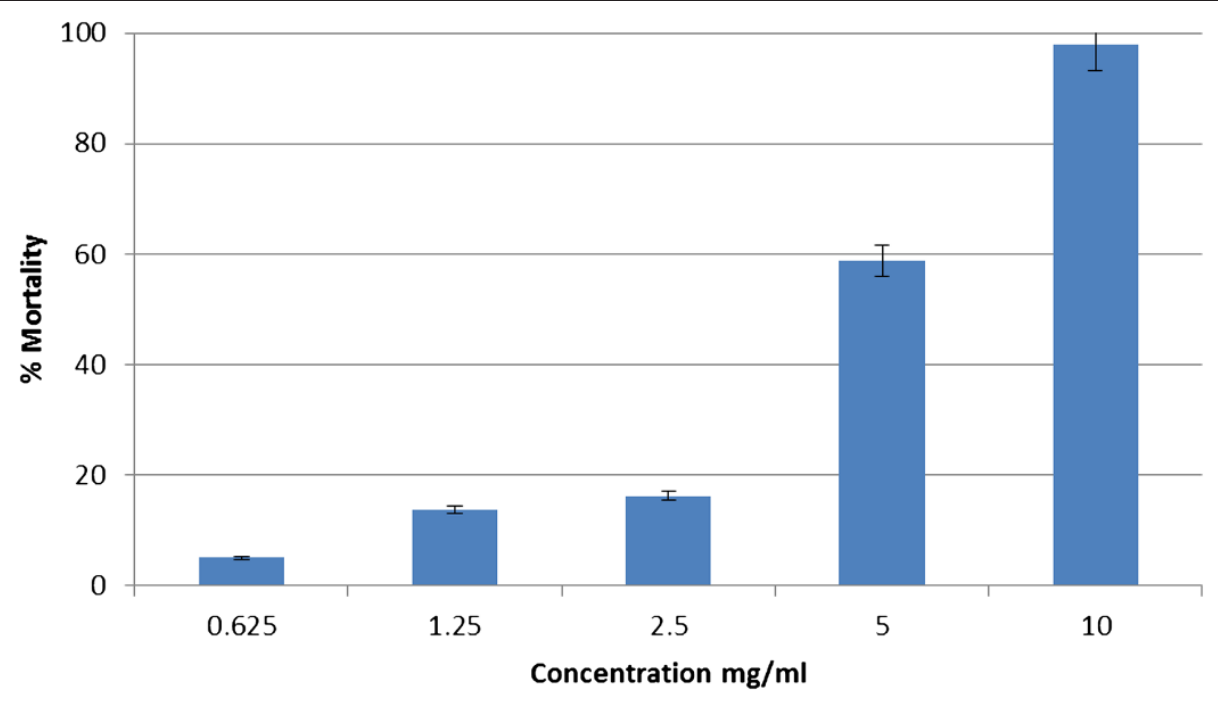

Figure 2 Dose-response assay of DCM extract of A. ferox against An. arabiensis.

to determine the $\mathrm{EC}_{50}$ value. The extract was tested at five concentrations ranging from 0.6 to $10 \mathrm{mg} / \mathrm{ml}$. After 24 hours of exposure, mosquito mortality ranging from 5 to $100 \%$ was observed (Figure 2) and an $\mathrm{EC}_{50}$ value of $4.92 \mathrm{mg} / \mathrm{ml}$ was recorded. The activity of this extract may be due to various compounds, such as phenolics, terpenoids, and alkaloids that exist in plants, and they may jointly or individually contribute to the insecticidal, ovicidal, repellent and antifeeding activities against various insect species [34]. Aloe ferox has been reported to contain compounds such as chromones, anthraquinones, anthrones, anthone-C-glycosides [27]. Therefore, the observed adulticidal activity of the DCM extract of $A$. ferox leaves may be attributed to these compounds. The adulticidal activity of the DCM extract of $A$. ferox against An. arabiensis is reported for the first time in this study.

\section{Conclusions}

The obtained results indicate that the DCM extract of $A$. ferox leaves has potential to be developed as an insecticide against $A n$. arabiensis mosquitoes. However, further studies to evaluate its toxicity and effects on non-target organisms and the environment need to be conducted. Studies aimed at isolation and identification of active compounds are in progress. Evaluation of adulticidal activity of the DCM extract of $A$. ferox leaves against other medical-important mosquito species is also considered. The results of the present study could be useful in promoting research aimed at the development of new agents for mosquito control based on bioactive chemical compounds from indigenous plant sources.

\section{Competing interests}

The authors declare that they have no competing interests.
Authors' contributions

EJM conducted the experiments and wrote the manuscript. RM, JCC, JFF and JVS provided scientific inputs. All authors read and approved the manuscript.

\section{Acknowledgments}

The authors are grateful to the South African Medical Research Council for financial support. Thanks are also due to Mr Jabulani Zikhali and Mr Ashokoomar Saikoolal for their assistance with the collection of plant materials and conducting adulticidal assay, respectively.

Received: 15 January 2014 Accepted: 27 April 2014

Published: 6 May 2014

\section{References}

1. Becker N, Petrić D, Zgomba M: Mosquitoes and Their Control. New York: Kluwer Academic/Plenum Publishers; 2003.

2. Taubes G: Vaccines: searching for a parasite's weak spot. Science 2000, 290:434-437.

3. WHO: World Malaria Report. Geneva: World Health Organization; 2011.

4. Blumberg L, Frean J: Malaria control in South Africa - challenges and successes. S Afr Med J 2007, 97:1193-1197.

5. Maharaj R, Mthembu DJ, Sharp BL: Impact of DDT reintroduction on malaria transmission in KwaZulu-Natal. S Afr Med J 2005, 95:871-874.

6. Department of Health: Prevalence and Distribution of Malaria in South Africa: Annual report. Pretoria: South Africa; 2007.

7. Gerritsen AAM, Kruger P, Van der Loeff MFS, Grobusch MP: Malaria incidence in Limpopo Province, South Africa, 1998-2007. Malar J 2008, 7:162.

8. Pillay P, Maharaj VJ, Smith PJ: Investigating South African plants as a source of new antimalaria drugs. J Ethnopharmacol 2008, 119:438-454.

9. WHO: Indoor Residual Spraying: Use of Indoor Residual Spraying for Scaling Up Global Malaria Control and Elimination. Geneva: World Health Organization; 2006.

10. WHO: The Use of DDT in Malaria Vector Control. Geneva: World Health Organization; 2011.

11. Mabaso MLH, Sharp B, Lengeler C: Historical review of malaria control in southern Africa with emphasis on the use of indoor residual housespraying. Trop Med Int Health 2004, 9:846-856.

12. Casimiro S, Coleman M, Mohloai P, Hemingway J, Sharp BL: Insecticide resistance in Anopheles funestus (Diptera: Culicidae) from Mozambique. $J$ Med Entomol 2007, 43:267-275.

13. Mendis K, Rietveld A, Warsame M, Bosman A, Greenwood B, Wernsdorfer $\mathrm{WH}$ : From malaria control to eradication: The WHO perspective. Trop Med Int Health 2009, 14:802-809. 
14. Greenwood B: Can malaria be eliminated? Trans R Soc Trop Med Hyg 2009, 103S:S2-S5.

15. Van den Berg $\mathrm{H}$ : Global status of DDT and its alternatives for use in vector control to prevent disease. Environ Health Persp 2009, 117:1656-1663.

16. Kamaraj C, Rahuman AA, Bagavan A, Abduz ZA, Elango G, Kandan P, Rajakumar G, Marimuthu S, Santhoshkumar T: Larvicidal efficacy of medicinal plant extract against Anopheles stephensi and Culex quinquefasciatus (Diptera: Culicidae). Trop Biomed 2010, 27:211-219.

17. Tiwary M, Naik SN, Tewary DK, Mittal PK, Yadav S: Chemical composition and larvicidal activities of the essential oil of Zanthoxylum armatum DC (Rutaceae) against three mosquito vectors. J Vector Borne Dis 2007, 44:198-204.

18. Rahuman AA, Venkatesan P, Gopalakrishnan G: Mosquito larvicidal activity of oleic and linoleic acids isolated from Citrullus colocynthis (Linn.) Schrad. Parasitol Res 2008, 103:1383-1390.

19. Balandrin MF, Klocke JA, Wurtele ES, Bollinger WH: Natural plant chemicals: sources of industrial and medicinal materials. Science 1985, 228:1154-1160.

20. Yang $P, M a Y, Z$ Zheng $S$ : Adulticidal activity of five essential oils against Culex pipiens quinquefasciatus. J Pestic Sci 2005, 30:84-89.

21. Tewary DK, Bhardwaj A, Shanker A: Pesticidal activities in five medicinal plants collected from mid hills of western Himalayas. Ind Crop Prod 2005, 22:241-247.

22. Chansang U, Zahiri AS, Bansiddhi J, Boonruad T, Thonsrirak P, Mingmuang J, Benjapong N, Mulla MS: Mosquito larvicidal activity of aqueous extracts of long pepper (Piper retrofractum Vahl) from Thailand. J Vector Ecol 2005, 30:195-200.

23. Broussalis AM, Ferraro GE, Maritino VS, Pinzón R, Coussio JD, Alvarez JC: Argentine plants as potential source of insecticidal compounds. J Ethnopharmacol 1999, 67:219-223.

24. Mavundza EJ, Maharaj R, Finnie JF, Van Staden J: An ethnobotanical survey of mosquito repellent plants in uMkhanyakude district, KwaZulu-Natal Province, South Africa. J Ethnopharmacol 2011, 137:1516-1520.

25. National Research Council: Guide for the Care and Use of Laboratory Animals. Washington: National Academy Press; 1996.

26. WHO: Guidelines for Testing Mosquitoes Adulticides for Indoor Residual Spraying and Treatment of Mosquito Nets. Geneva: World Health Organization; 2006.

27. Chen W, Van Wyk BE, Vermaak I, Viljoen AM: Cape aloes - A review of the phytochemistry, pharmacology and commercialisation of Aloe ferox. Phytochem Lett 2012, 5:1-12.

28. Nathan SS, Kalaivan K, Sehoon K: Effects of Dysoxylum malabaricum Bedd. (Meliaceae) extract on the malarial vector Anopheles stephensi Liston (Diptera: Culicidae). Bioresource Technol 2006, 97:2077-2083.

29. Choochote W, Tuetun B, Kanjanapothi D, Rattanachanpichai E, Chaithong U, Chaiwong P, Jitpakdi A, Tippawangkosol P, Riyong D, Pitasawat B: Potential of crude seed extract of celery, Apium graveolens L., against the mosquito Aedes aegypti (L.) (Diptera: Culicidae). J Vector Ecol 2004, 29:340-346.

30. Kovendan K, Murugan K, Kumar PM, Thiyagarajan P, William SM: Ovicidal, repellent, adulticidal and field evaluations of plant extract against dengue, malaria and filarial vectors. Parasitol Res 2013, 112:1205-1219.

31. Choochote W, Chaiyasit D, Kanjanapothi B, Rattanachanpichai E, Jitpakdi A, Tuetun B, Pitasawat B: Chemical composition and anti-mosquito potential of rhizome extract and volatile oil derived from Curcuma aromatic against Aedes aegypti (Diptera: Culcidae). J Vector Ecol 2005, 30:302-309.

32. Kamaraj C, Rahuman AA, Mahapatra A, Bagavan A, Elango G: Insecticidal and larvicidal activities of medicinal plant extracts against mosquitoes. Parasitol Res 2010, 107:1337-1349.

33. Nathan SS, Savitha G, George DK, Narmadha A, Suganya L, Chung PG: Efficacy of Melia azedarach L. extract on the malaria vector Anopheles stephensi Liston (Diptera: Culicidae). Bioresource Technol 2006, 97:1316-1323.

34. Yang YC, Lee HS, Lee SH, Clark JM, Ahn YJ: Ovicidal and adulticidal activities of Cinnamomum zeylanicum bark essential oil compounds and related compounds against Pediculus humanus capitis (Anoplura: Pediculicidae). Int J Parasitol 2005, 35:1595-1600.

doi:10.1186/1475-2875-13-173

Cite this article as: Mavundza et al: Screening for adulticidal activity against Anopheles arabiensis in ten plants used as mosquito repellent in South Africa. Malaria Journal 2014 13:173.

\section{Submit your next manuscript to BioMed Central and take full advantage of:}

- Convenient online submission

- Thorough peer review

- No space constraints or color figure charges

- Immediate publication on acceptance

- Inclusion in PubMed, CAS, Scopus and Google Scholar

- Research which is freely available for redistribution 